OPEN ACCESS

Edited by:

Xuesheng Liu,

First Affiliated Hospital of Anhui

Medical University, China

Reviewed by:

Yuanlin Dong,

Massachusetts General Hospital and

Harvard Medical School,

United States

Diansan Su,

Shanghai JiaoTong University, China

*Correspondence:

Tao Zhu

739501155@qq.com

Chan Chen

xychenchan@gmail.com

tThese authors have contributed equally to this work and share first authorship

Specialty section:

This article was submitted to

Perception Science,

a section of the journal

Frontiers in Neuroscience

Received: 07 July 2021

Accepted: 20 August 2021

Published: 22 September 2021

Citation:

Zhang $X$, Gao $R$, Zhang $C$, Chen $H$, Wang $R$, Zhao $Q$, Zhu T and Chen $C$ (2021) Evidence for Cognitive Decline in Chronic Pain: A Systematic Review and Meta-Analysis.

Front. Neurosci. 15:737874. doi: 10.3389/fnins.2021.737874

\section{Evidence for Cognitive Decline in Chronic Pain: A Systematic Review and Meta-Analysis}

\author{
Xueying Zhang ${ }^{1 \dagger}$, Rui Gao ${ }^{1 \dagger}$, Changteng Zhang ${ }^{1}$, Hai Chen ${ }^{2}$, Ruiqun Wang ${ }^{1}$, Qi Zhao', \\ Tao $\mathrm{Zhu}^{1 *}$ and Chan Chen ${ }^{1 *}$ \\ 1 Department of Anesthesiology and Translational Neuroscience Center, West China Hospital, Sichuan University, Chengdu, \\ China, ${ }^{2}$ Precision Medicine Research Center, West China Hospital, Sichuan University, Chengdu, China
}

Background: People with chronic pain (CP) sometimes report impaired cognitive function, including a deficit of attention, memory, executive planning, and information processing. However, the association between $\mathrm{CP}$ and cognitive decline was still not clear. Our study aimed to assess the association of CP as a risk factor with cognitive decline among adults.

Methods: We included data from clinical studies. Publications were identified using a systematic search strategy from PubMed, Embase, and Cochrane Library databases from inception to October 10, 2020. We used the mean cognitive outcome data and the standard deviations from each group. The standardized mean difference (SMD) or odds ratio (OR), and 95\% confidence intervals $(\mathrm{Cl})$ were performed for each cognitive decline outcome. $I^{2}$-values were assessed to quantify the heterogeneities.

Results: We included 37 studies with a total of 52,373 patients with CP and 80,434 healthy control participants. Because these studies used different evaluative methods, we analyzed these studies. The results showed CP was associated with cognitive decline when the short-form 36 health survey questionnaire (SF-36) mental component summary (SMD $=-1.50,95 \% \mathrm{Cl}=-2.19$ to -0.81$)$, the Montreal cognitive assessment $(\mathrm{SMD}=-1.11,95 \% \mathrm{Cl}=-1.60$ to -0.61$)$, performance validity testing $(\mathrm{SMD}=3.05$, $95 \% \mathrm{Cl}=1.74$ to 4.37$)$, or operation span (SMD $=-1.83,95 \% \mathrm{Cl}=-2.98$ to -0.68$)$ were used. However, we got opposite results when the studies using International Classification of Diseases and Related Health Problems classification (OR $=1.58,95 \%$ $\mathrm{Cl}=0.97$ to 2.56$)$, the Mini-Mental State Examination $(\mathrm{SMD}=-0.42,95 \% \mathrm{Cl}=-0.94$ to 0.10; $\mathrm{OR}=1.14,95 \% \mathrm{Cl}=0.91$ to 1.42 ), and Repeatable Battery for the Assessment of Neuropsychological Status memory component $(\mathrm{SMD}=-0.06,95 \% \mathrm{Cl}=-0.37$ to 0.25$)$.

Conclusion: There may be an association between CP and the incidence of cognitive decline when some cognitive, evaluative methods were used, such as short-form 36 health survey questionnaire, Montreal cognitive assessment, performance validity testing, and operation span.

Keywords: chronic pain, cognitive decline, memory, dementia, neuropathology 


\section{INTRODUCTION}

Pain is a multidimensional experience that includes sensory discrimination, emotional motivation, and cognitive evaluation interacting with each other (Treede et al., 2019). And chronic pain (CP) refers to the persistent pain after healing, which is considered to have occurred or exist without tissue damage. Unfortunately, millions of people in today's world are debilitated by various $\mathrm{CP}$ types such as headaches, arthritis, and backache. Chronic pain is a common, complex, and distressing problem that has a major impact on society and individuals. The 2016 Global Burden of Disease Study highlighted that pain and

TABLE 1 | Characteristics of the included studies.

\begin{tabular}{|c|c|c|c|c|c|c|c|c|}
\hline \multirow[t]{2}{*}{ Study } & \multirow[t]{2}{*}{ Geographic location } & \multirow[t]{2}{*}{ Pain type } & \multicolumn{6}{|c|}{ Participants } \\
\hline & & & $N$ & Age & Gender & $\mathbf{N}$ & Age & Gender \\
\hline Butterworth2014 & Australia & FP & 27 & $49.5 \pm 8.7$ & $22 \mathrm{~F}$ & 35 & $46.9 \pm 8.8$ & $27 \mathrm{~F}$ \\
\hline Coppieters2015 & Belgium & WAD & 16 & $41.6 \pm 11.4$ & $13 \mathrm{~F}$ & 22 & $38.0 \pm 13.9$ & $14 \mathrm{~F}$ \\
\hline & & LBP & 23 & $47.6 \pm 12$ & $22 \mathrm{~F}$ & 23 & $45 \pm 8.6$ & $21 \mathrm{~F}$ \\
\hline Docking2014 & UK & LBP & 45 & $46.9 \pm 11.9$ & $34 \mathrm{~F}$ & 45 & $45.1 \pm 10.4$ & $34 \mathrm{~F}$ \\
\hline Dos Santos2016 & Brasil & $\mathrm{CP}$ & 45 & N/A & N/A & 45 & $\mathrm{~N} / \mathrm{A}$ & $\mathrm{N} / \mathrm{A}$ \\
\hline Fernández2016 & Spain & FP & 22 & $47.9 \pm 11.0$ & $11 \mathrm{~F}$ & 22 & $47.2 \pm 11$ & $11 \mathrm{~F}$ \\
\hline Gu2019 & China & $\mathrm{CP}$ & 25 & $39.9 \pm 9.9$ & $11 \mathrm{~F}$ & 32 & $33.6 \pm 8.7$ & $9 F$ \\
\hline Kaiho2017 & Japan & $\mathrm{CP}$ & 10,702 & $73.93 \pm 5.86$ & $4,730 \mathrm{~F}$ & 3,000 & $73.2 \pm 6$ & $1,858 \mathrm{~F}$ \\
\hline Ko2013 & Korea & CAP & 21 & $66.1 \pm 11.4$ & $8 \mathrm{~F}$ & 48 & $64.1 \pm 13.1$ & $10 \mathrm{~F}$ \\
\hline Kotb2020 & Saudi Arabia & headache & 100 & $35.31 \pm 6.95$ & $60 \mathrm{~F}$ & 105 & $35.51 \pm 7.35$ & $63 \mathrm{~F}$ \\
\hline Latysheva2020 & Russia & headache & 144 & $42.5 \pm 3.17$ & $132 \mathrm{~F}$ & 44 & $37 \pm 5.5$ & $40 \mathrm{~F}$ \\
\hline Martinsen2014 & Sweden & FM & 29 & $49.8 \pm 9.75$ & N/A & 31 & $46.3 \pm 10.7$ & N/A \\
\hline Meeks2008 & USA & $\mathrm{CP}$ & 92 & $79.4 \pm 6.8$ & $56 \mathrm{~F}$ & 56 & $81 \pm 6.1$ & $33 F$ \\
\hline Meeus2015 & Belgium & WAD & 15 & $41.6 \pm 11.4$ & $3 F$ & 16 & $40.9 \pm 13.4$ & $6 F$ \\
\hline Hirase2020 & Japan & LBP,KP & 421 & $75.79 \pm 6.5$ & $288 \mathrm{~F}$ & 368 & $73.65 \pm 5.8$ & $218 \mathrm{~F}$ \\
\hline Ojeda2017 & Spain & NP,MP,FM & 254 & $47.42 \pm 8.8$ & N/A & 72 & $40 \pm 11.11$ & N/A \\
\hline Öncü2015 & Turkey & FM & 86 & $32.3 \pm 6.0$ & N/A & 75 & $32.1 \pm 7.7$ & N/A \\
\hline Shega2010 & Canada & Non-CAP & 1,813 & $79.9 \pm 6.0$ & $1,222 \mathrm{~F}$ & 3,273 & $79.4 \pm 6.1$ & $1,817 \mathrm{~F}$ \\
\hline Shega2012 & Canada & $\mathrm{CP}$ & 1,332 & $79.4 \pm 5.8$ & $922 \mathrm{~F}$ & 2,435 & $78.9 \pm 5.8$ & $1,359 F$ \\
\hline Tzeng2017 & Taiwan & headache & 3,630 & $\mathrm{~N} / \mathrm{A}$ & $2,463 F$ & 10,860 & $\mathrm{~N} / \mathrm{A}$ & $7,389 F$ \\
\hline vander Leeuw2018 & USA & $\mathrm{CP}$ & 285 & N/A & N/A & 156 & $\mathrm{~N} / \mathrm{A}$ & N/A \\
\hline vander Leeuw2019 & USA & $\mathrm{CP}$ & 692 & $74.38 \pm 6.59$ & $480 \mathrm{~F}$ & 2,552 & $74.29 \pm 6.81$ & $1,430 \mathrm{~F}$ \\
\hline Veronese2018 & Italy & $\mathrm{CP}$ & 2,317 & $65.5 \pm 9.5$ & $1,244 \mathrm{~F}$ & 4,198 & $64.2 \pm 9.7$ & $2,674 \mathrm{~F}$ \\
\hline Walteros2011 & Spain & FM & 15 & $50.4 \pm 4.6$ & N/A & 15 & $49.0 \pm 6.7$ & N/A \\
\hline Weiner2006 & USA & LBP & 163 & $73.6 \pm 5.2$ & $80 \mathrm{~F}$ & 160 & $73.5 \pm 4.8$ & $66 \mathrm{~F}$ \\
\hline Whitlock 2017 & USA & $\mathrm{CP}$ & 1,120 & $73.8 \pm 5.4$ & $851 \mathrm{~F}$ & 8,945 & $73.6 \pm 5.2$ & $5,197 \mathrm{~F}$ \\
\hline
\end{tabular}

FP, foot pain; WAD, Whiplash-associated disorder; FM, Fibromyalgia syndrome; LBP, low back pain; CP, chronic pain; CAP, cancer pain; KP, knee pain; NP, neuropathic pain; MP, musculoskeletal pain; PHN, postherpetic neuralgia; UK, United Kingdom; USA, United States of America; N, number; F, female; N/A, not applicable. 
pain-related diseases were major contributors to the global burden of disability and disease (GBD Disease and Injury Incidence and Prevalence Collaborators, 2017). The annual costs of CP in direct medical costs are very high, and the loss of productivity it brings is huge. Therefore, pain relief is an important topic in clinical work and scientific research. Moreover, increased studies have shown that CP had many adverse outcomes, such as mood disorder, weight loss, daily functional loss, lower quality of life, and higher costs of health (Saraiva et al., 2018). Interestingly, CP seems to cause changes in cognitive function, which is another critical problem.

Cognitive decline could involve cognitive impairment in one or several areas, such as learning and memory, executive function, general cognitive functioning, attention, and social cognition (Sachdev et al., 2014). Moreover, cognitive decline has been reported to significantly impact medical compliance, workability, interpersonal interaction, and quality of life. Clinical studies have shown that CP was related to attention, memory, executive planning, and information processing (Berryman et al., 2013, 2014; Mazza et al., 2018). A longitudinal study of elders found persistent pain was associated with memory decline (Whitlock et al., 2017). A meta-analysis of longitudinal studies showed that headache was associated with a higher risk of dementia (Wang et al., 2018). However, another meta-analysis contained 10 prospective longitudinal studies that showed persistent pain was not associated with the incidence of cognitive decline (De Aguiar et al., 2020). A study also demonstrated pain was not associated with incident cognitive impairment in any of the three cognitive domains evaluated (attention, memory, and executive functioning) (Van Der Leeuw et al., 2018a).

The relation between pain and cognitive decline is complex, and pain may impair cognition by some mechanisms (Moriarty et al., 2011). Some studies suggested that the pain was associated with brain plasticity and structural changes in different cortical regions associated with learning, memory, fear, and emotional responses (Mazza et al., 2018). In addition, Moriarty et al. (2011) demonstrated that pain and cognition might share some common transduction pathways. Because pain is treatable, defining whether it is a risk factor of cognitive decline can promote targeted screening, preventive, and therapeutic interventions. Therefore, we applied a systematic review and meta-analysis to determine the evidence that $\mathrm{CP}$ is associated with cognitive decline.

\section{METHODS}

\section{Search Strategy}

We searched the PubMed, Embase, and Cochrane Library from inception to October 10, 2020. Each database was searched separately. We searched synonyms of "chronic pain" and "cognitive decline." Synonyms for "chronic pain" included "Chronic Pains," "Pains, Chronic," "Pain, Chronic," "Widespread Chronic Pain," "Chronic Pain, Widespread," "Chronic Pains, Widespread," "Pain, Widespread Chronic," "Pains, Widespread Chronic," and "Widespread Chronic Pains." Synonyms for "Cognitive Decline" included "Cognitive
Dysfunctions," "Dysfunction, Cognitive," "Dysfunctions, Cognitive," "Cognitive Impairments," "Cognitive Impairment," "Impairment, Cognitive," "Impairments, Cognitive," "Mild Cognitive Impairment," "Cognitive Impairment, Mild," "Cognitive Impairments, Mild," "Impairment, Mild Cognitive," "Impairments, Mild Cognitive," "Mild Cognitive Impairments," "Mild Neurocognitive Disorder," "Disorder, Mild Neurocognitive," "Disorders, Mild Neurocognitive," "Mild Neurocognitive Disorders," "Neurocognitive Disorder, Mild," "Neurocognitive Disorders, Mild," "Cognitive Decline," “Cognitive Declines," "Decline, Cognitive," "Declines, Cognitive," "Mental Deterioration," "Deterioration, Mental," "Deteriorations, Mental," "Mental Deteriorations," "Cognitive disorders," "Disorder, Cognition," "Disorders, Cognition," "Dementia," and "Dementias." Citations related to cognitive decline and $\mathrm{CP}$ were retrieved and exported to ENDNOTE, where duplicates were removed, and articles were reviewed. This systematic review and meta-analysis were followed according to Cochrane Collaboration (Higgins and Green, 2008) and Preferred Reporting Items for Systematic Reviews and MetaAnalyses Statement guidelines (Moher et al., 2009). The authors have completed the Preferred Reporting Items for Systematic Reviews and Meta-Analyses reporting checklist (Supplementary Material).

\section{Study Selection}

In this meta-analysis, we included studies that investigated cognitive performance in a CP population and compared this performance with that of healthy controls. Two coauthors (Xueying Zhang and Qi Zhao) independently reviewed the titles and abstracts of the retrieved citations. First, we excluded studies that were not investigating the association of pain and cognitive decline. The discrepancy between these two coauthors was reviewed by another author (Rui Gao). Then, full texts of

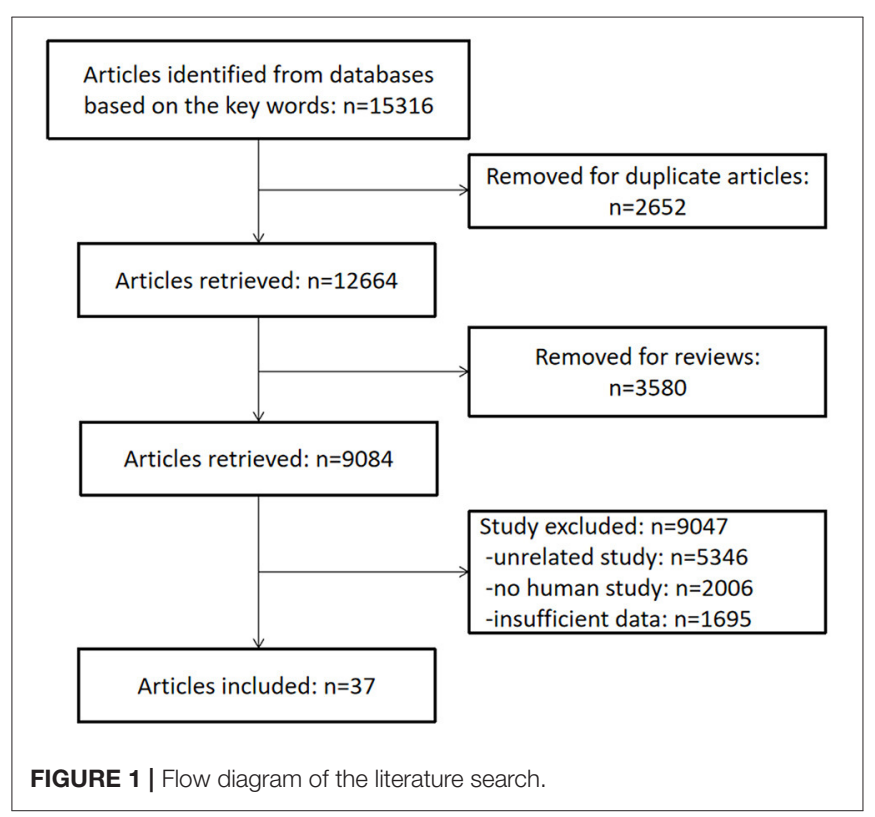


TABLE 2 | Risk of bias of included studies.

\begin{tabular}{|c|c|c|c|c|c|c|c|c|c|c|c|c|c|c|}
\hline Study (ref.) & $\begin{array}{l}\text { Are cases } \\
\text { represe- } \\
\text { ntative? }\end{array}$ & $\begin{array}{l}\text { Were initial } \\
\text { numbers } \\
\text { recorded? }\end{array}$ & $\begin{array}{l}\text { Were cases } \\
\text { diagnosed } \\
\text { according } \\
\text { to accepted } \\
\text { criteria? }\end{array}$ & $\begin{array}{l}\text { Were } \\
\text { controls } \\
\text { using the } \\
\text { same } \\
\text { diagnostic } \\
\text { criteria? }\end{array}$ & $\begin{array}{l}\text { Were } \\
\text { psychiatric } \\
\text { disorders } \\
\text { screened } \\
\text { for? }\end{array}$ & $\begin{array}{l}\text { Were } \\
\text { outcome } \\
\text { assessors } \\
\text { blinded to } \\
\text { group } \\
\text { status? }\end{array}$ & $\begin{array}{l}\text { Were } \\
\text { sample } \\
\text { sizes } \\
\text { calculated } \\
\text { a priori? }\end{array}$ & $\begin{array}{l}\text { Were } \\
\text { confounding } \\
\text { variables } \\
\text { controlled } \\
\text { for? }\end{array}$ & $\begin{array}{l}\text { Was } \\
\text { subgroup } \\
\text { evaluation } \\
\text { appropriate? }\end{array}$ & $\begin{array}{l}\text { Were there } \\
\text { any missing } \\
\text { data? } \\
?\end{array}$ & $\begin{array}{l}\text { Appropriate } \\
\text { methods to } \\
\text { deal with } \\
\text { missing } \\
\text { data? }\end{array}$ & $\begin{array}{l}\text { Were all } \\
\text { outcomes } \\
\text { and groups } \\
\text { reported? }\end{array}$ & $\begin{array}{l}\text { Are the } \\
\text { cognitive } \\
\text { tests used } \\
\text { valid? }\end{array}$ & $\begin{array}{l}\text { Are the } \\
\text { cognitive } \\
\text { tests used } \\
\text { reliable? }\end{array}$ \\
\hline Butterworth2014 & Y & Y & Y & Y & $\mathrm{N}$ & $?$ & $N$ & Y & Y & Y & Y & Y & Y & Y \\
\hline Coppieters2015 & Y & Y & Y & Y & Y & $?$ & $N$ & Y & Y & $\mathrm{N}$ & $\mathrm{N}$ & Y & Y & Y \\
\hline Demirci2002 & Y & Y & Y & Y & Y & $?$ & $\mathrm{~N}$ & Y & Y & Y & Y & Y & Y & Y \\
\hline Docking2014 & Y & Y & N & Y & Y & $?$ & $\mathrm{~N}$ & Y & Y & Y & Y & Y & Y & Y \\
\hline Dos Santos2016 & Y & Y & Y & Y & Y & $?$ & $\mathrm{~N}$ & Y & Y & Y & Y & Y & Y & Y \\
\hline Fernández2016 & Y & Y & Y & Y & N & $?$ & $\mathrm{~N}$ & Y & Y & $\mathrm{N}$ & $\mathrm{N}$ & Y & Y & Y \\
\hline Gu2018 & Y & Y & Y & Y & Y & $?$ & N & Y & Y & Y & Y & Y & Y & Y \\
\hline Hagen2013 & Y & Y & Y & Y & N & $?$ & $\mathrm{~N}$ & Y & Y & Y & Y & Y & Y & Y \\
\hline Ikram2019 & Y & Y & Y & Y & Y & $?$ & Y & Y & Y & $\mathrm{N}$ & $\mathrm{N}$ & Y & Y & Y \\
\hline Jonsson2011 & Y & Y & Y & Y & N & $?$ & N & Y & Y & Y & Y & Y & Y & Y \\
\hline Jordan2018 & Y & Y & Y & Y & $N$ & $?$ & $N$ & Y & Y & Y & Y & Y & Y & Y \\
\hline Kaiho2017 & Y & Y & Y & Y & $\mathrm{N}$ & $?$ & $\mathrm{~N}$ & Y & Y & Y & Y & Y & Y & Y \\
\hline Ko2013 & Y & Y & Y & Y & Y & $?$ & $\mathrm{~N}$ & Y & Y & $\mathrm{N}$ & $\mathrm{N}$ & Y & Y & Y \\
\hline Kotb2020 & Y & Y & Y & Y & Y & $?$ & $\mathrm{~N}$ & Y & Y & $\mathrm{N}$ & $\mathrm{N}$ & Y & Y & Y \\
\hline Latysheva2020 & Y & Y & Y & Y & Y & $?$ & $\mathrm{~N}$ & Y & Y & $\mathrm{N}$ & $\mathrm{N}$ & Y & Y & Y \\
\hline Martinsen2014 & Y & Y & Y & Y & Y & $?$ & $\mathrm{~N}$ & Y & Y & $\mathrm{N}$ & $\mathrm{N}$ & Y & Y & Y \\
\hline Meeks2008 & Y & Y & N & Y & Y & $?$ & $N$ & Y & Y & Y & Y & Y & Y & Y \\
\hline Meeus2015 & Y & Y & Y & Y & Y & $?$ & $N$ & Y & Y & $N$ & $\mathrm{~N}$ & Y & Y & Y \\
\hline Hirase2020 & Y & Y & N & Y & Y & $?$ & $N$ & Y & Y & $N$ & $\mathrm{~N}$ & Y & Y & Y \\
\hline Ojeda2017 & Y & Y & Y & Y & Y & $?$ & $N$ & Y & Y & $\mathrm{N}$ & $\mathrm{N}$ & Y & Y & Y \\
\hline Öncü2015 & Y & Y & Y & Y & Y & $?$ & $N$ & Y & Y & $N$ & $\mathrm{~N}$ & Y & Y & Y \\
\hline Pickering2013 & Y & Y & Y & Y & Y & $?$ & $N$ & Y & Y & $N$ & $\mathrm{~N}$ & Y & Y & Y \\
\hline $\begin{array}{l}\text { Pidal- } \\
\text { Miranda2018 }\end{array}$ & Y & Y & Y & Y & Y & $?$ & $N$ & Y & Y & $N$ & N & Y & Y & Y \\
\hline Pirrotta 2013 & Y & Y & Y & Y & Y & $?$ & Y & Y & Y & $Y$ & Y & Y & Y & Y \\
\hline Qu2017 & Y & Y & Y & Y & Y & $?$ & $N$ & Y & Y & $\mathrm{N}$ & N & Y & Y & Y \\
\hline Samartin2019 & Y & Y & Y & Y & Y & $?$ & $N$ & Y & Y & $N$ & $\mathrm{~N}$ & Y & Y & Y \\
\hline Santangelo2016 & Y & Y & Y & Y & Y & $?$ & $\mathrm{~N}$ & Y & Y & $\mathrm{N}$ & $\mathrm{N}$ & Y & Y & Y \\
\hline Schepker2016 & Y & Y & Y & Y & Y & $?$ & $\mathrm{~N}$ & Y & Y & $\mathrm{N}$ & $\mathrm{N}$ & Y & Y & Y \\
\hline Shega2010 & Y & Y & Y & Y & Y & $?$ & $\mathrm{~N}$ & Y & Y & $\mathrm{N}$ & $\mathrm{N}$ & Y & Y & Y \\
\hline Shega2012 & Y & Y & Y & Y & Y & $?$ & $\mathrm{~N}$ & Y & Y & $\mathrm{N}$ & $\mathrm{N}$ & Y & Y & Y \\
\hline Tzeng2017 & Y & Y & Y & Y & Y & $?$ & $N$ & Y & Y & Y & Y & Y & Y & Y \\
\hline
\end{tabular}




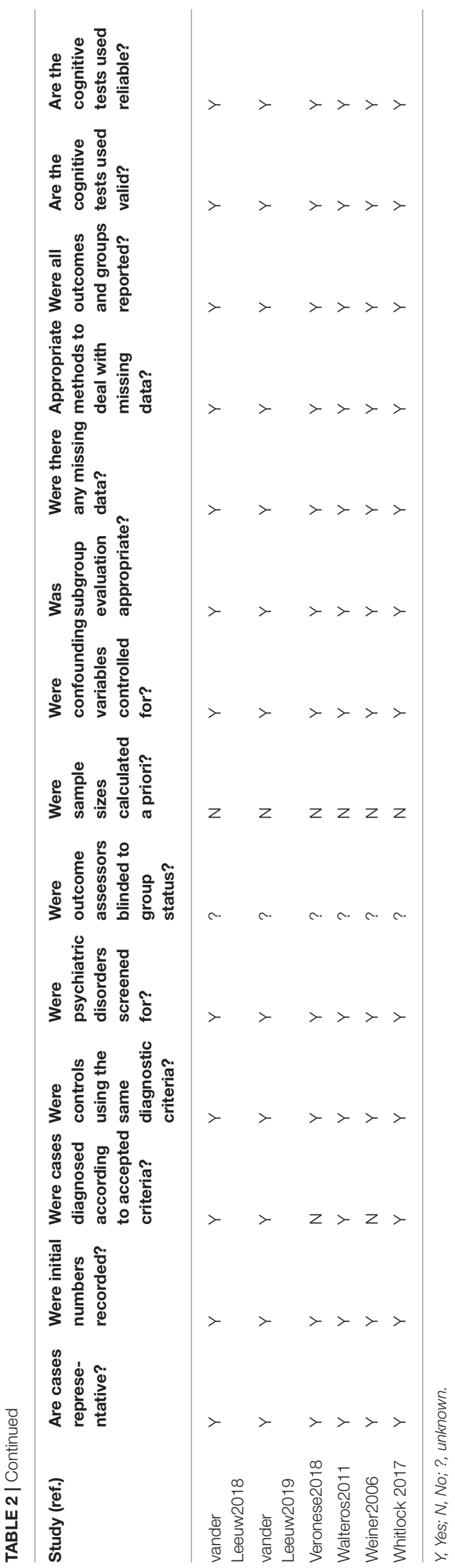

the selected citations were assessed independently for inclusion criteria by the same coauthors and using the same strategy.

We included randomized clinical trials, systematic reviews, and meta-analyses. We excluded editorials, case reports, and descriptive and cross-sectional studies. The definition of cognitive decline could be reported by incident cognitive impairment (binary outcomes) or a decline in cognitive performance (continuous outcomes). For pain assessment, we included studies reporting any kind of pain, except experimental pain.

\section{Data Extraction}

Two coauthors (Xueying Zhang and Changteng Zhang) independently read and extracted data from the included full-text citations. For each study included, we extracted this information: study publication year, geographic location where the study was performed, numbers, type of pain, age, and sex distribution of each group, mean age of participants, and number of female participants.

\section{Risk of Bias Assessment}

We constructed a risk of bias form based on relevant items from the Cochrane Collaboration risk of bias tool and relevant forms of bias relating to case-control study designs (Berryman et al., 2013). Two coauthors (Xueying Zhang and Qi Zhao) completed the bias of each study. Any disagreements were resolved through discussion or by the inclusion of a third reviewer (Rui Gao).

\section{Data Analysis}

Cognitive outcome data were divided according to different cognitive diagnosis methods. We used the mean cognitive outcome data and the standard deviations from each group. The standardized mean difference (SMD) of continuous data or odds ratio (OR) of binary data and $95 \%$ confidence intervals (CI) was performed for each cognitive decline outcome. $I^{2}$-values were assessed to quantify the heterogeneities. Data for each cognitive decline construct were pooled when results were available from at least two studies. Studies were excluded from the analysis if they did not have sufficient data.

\section{RESULTS}

\section{Characteristics of the Included Studies}

From the 15,316 records identified by the search methods, 37 studies (Demirci and Savas, 2002; Weiner et al., 2006; Meeks et al., 2008; Shega et al., 2010, 2012; Jonsson et al., 2011; Walteros et al., 2011; Ko et al., 2013; Pirrotta et al., 2013; Butterworth et al., 2014; Docking et al., 2014; Hagen et al., 2014; Martinsen et al., 2014; Pickering et al., 2014; Coppieters et al., 2015; Meeus et al., 2015; Öncü et al., 2015; Dos Santos Ferreira et al., 2016; Fernández-Lao et al., 2016; Santangelo et al., 2016; Schepker et al., 2016; Kaiho et al., 2017; Tzeng et al., 2017; Whitlock et al., 2017; Jordan et al., 2018; Ojeda et al., 2018; PidalMiranda et al., 2018; Qu et al., 2018; Van Der Leeuw et al., 2018b, 2020; Veronese et al., 2018; Gu et al., 2019; Ikram et al., 2019; Samartin-Veiga et al., 2019; Kotb et al., 2020; Latysheva 
et al., 2020; Nakai et al., 2020) were identified, a total of 52,373 patients with CP and 80,434 healthy control participants. These 37 studies included different types of CP: headache $(n=7)$; fibromyalgia syndrome (FM) $(n=6)$; low back pain $(n=$ $3)$; whiplash-associated disorder $(n=2)$; foot pain $(n=2)$; cancer pain $(n=1)$; low back pain and knee pain $(n=1)$; neuropathic pain $(n=1)$; musculoskeletal pain, neuropathic pain, and FM $(n=1)$; post-herpetic neuralgia $(n=1)$; noncancer pain $(n=1)$; and other unclassified CP $(n=13)$. Among these 37 studies, there were two studies that have invested two kinds of CP, so the total number is 39 . Of these 37 studies, cognitive decline was evaluated by different methods: MiniMental State Examination (MMSE) $(n=6)$, the short-form 36 health survey questionnaire (SF-36) mental component $(n=6)$, Montreal cognitive assessment (MOCA) $(n=4)$, International Classification of Diseases and Related Health Problems (ICD) classification $(n=4)$, Wechsler Adult Intelligence Scale (WAIS) $(n=4)$, performance validity testing (PVT) $(n=2)$, operation span (OSPAN) $(n=2)$, Repeatable Battery for the Assessment of Neuropsychological Status (RBANS) memory component $(n=2)$ (Table 1), Stroop test $(n=1)$, Memory Failures of Everyday (MFE-30) test $(n=1)$, Syndrom Kurz Test (SKT) $(n=1)$, Cognitive Performance Scale minimus data set (MDS) $(n=1)$, Telephone Interview for Cognitive Status (TICS) $(n=1)$, short test of mental status (STMS) $(n=1)$, and Cambridge Neuropsychological Test Automated Battery (CNTAB) $(n=1)$. Figure 1 describes the process of the study selection. Table 1 describes the characteristics of the included studies.

Only when at least two articles used the same method can be used for meta-analysis. Also, as for WAIS, the four studies used different parts of WAIS, so they could not be analyzed together. Furthermore, for SF-36, mental health and mental component summary are considered as two comparisons. Effects were expressed as SMD for continuous data and OR for binary data, and 95\% CIs were given for each study. Weights are from the random-effects analysis.

\section{Risk of Bias of Included Studies}

All studies were deemed to have a risk of bias. One hand is owing to the lack of blinding of the outcome assessors and patients. On the other hand, the bias of these studies was mainly in whether psychiatric disorders were screened for, sample sizes calculated $a$ priori (Table 2).

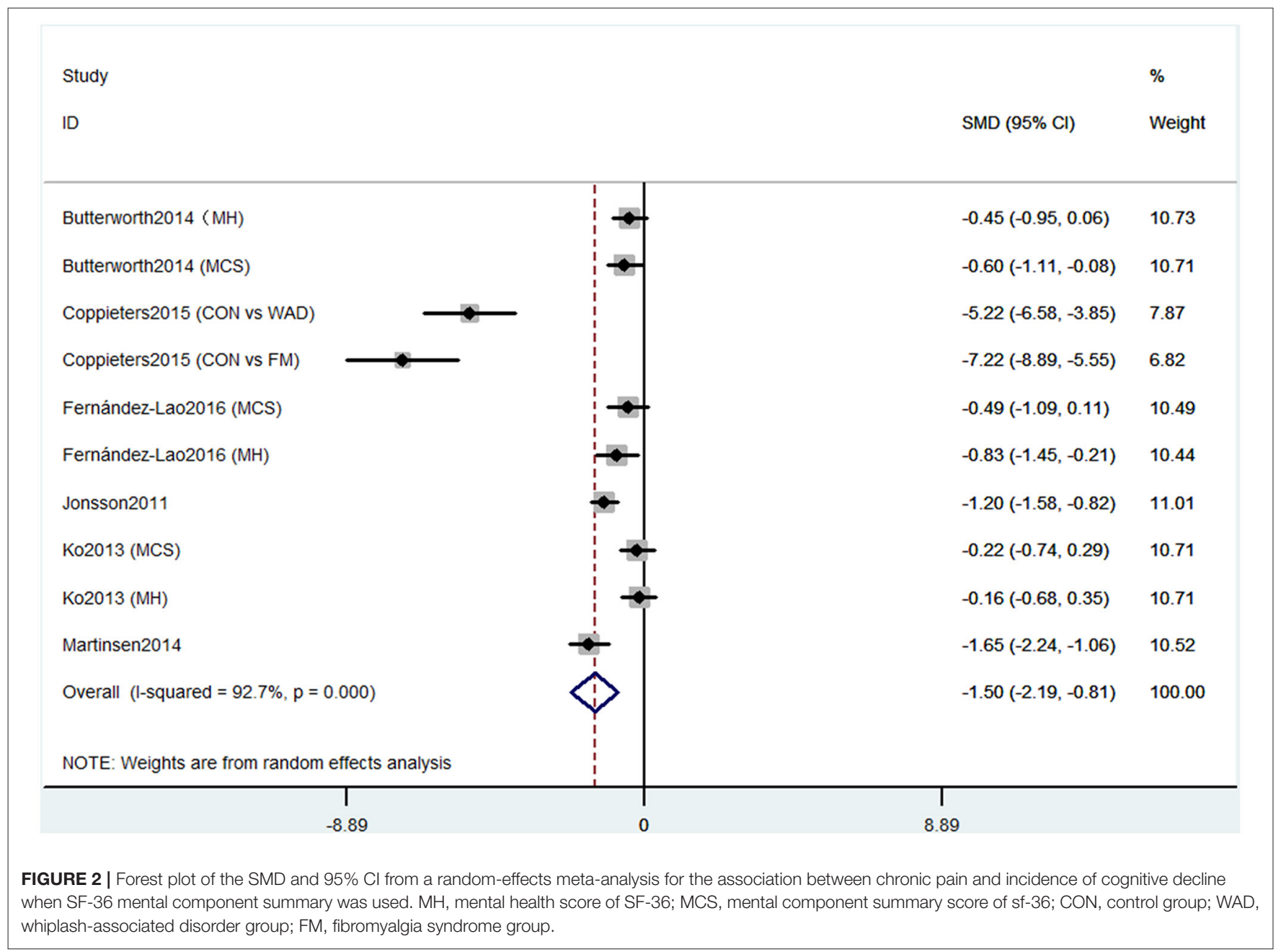


Study

ID
$\%$

SMD $(95 \% \mathrm{Cl}) \quad$ Weight

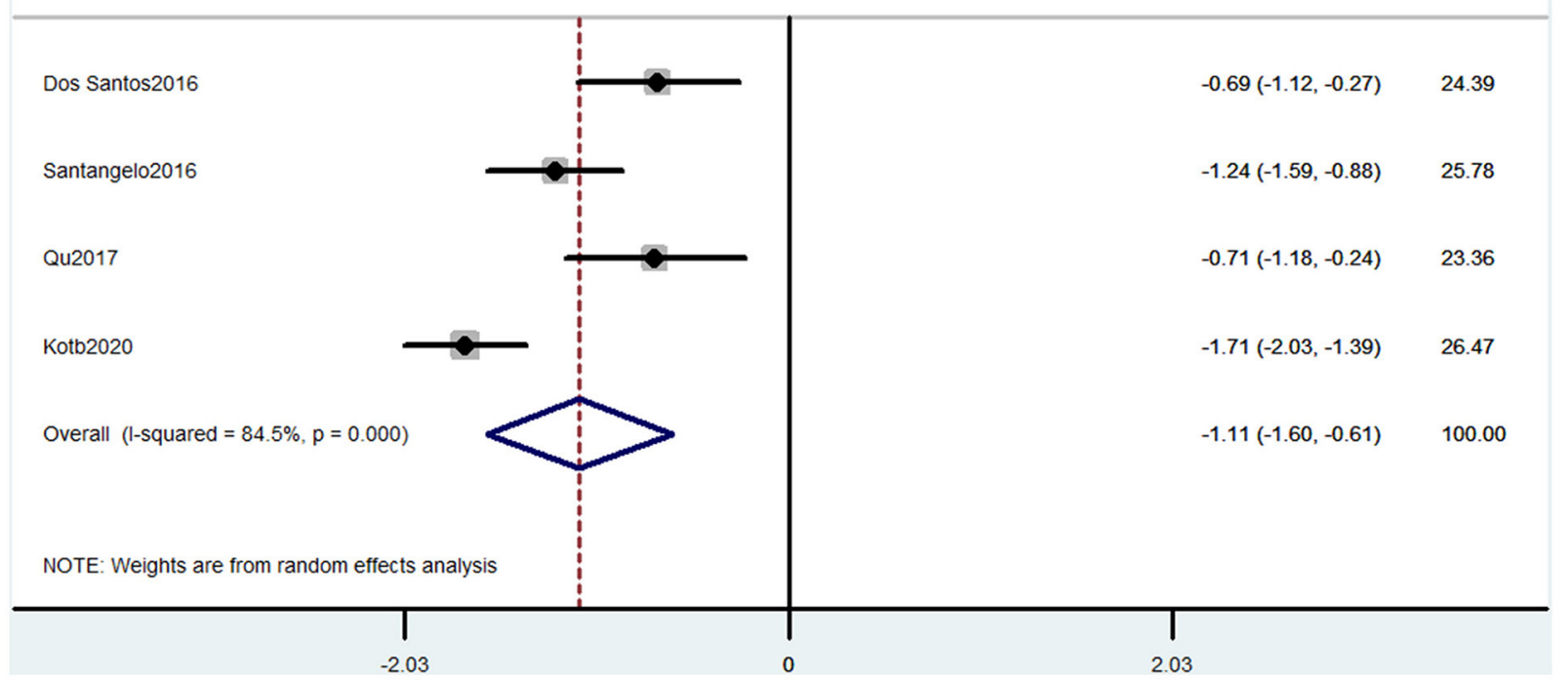

FIGURE 3 | Forest plot of the SMD and 95\% Cl from a random-effects meta-analysis for the association between chronic pain and incidence of cognitive decline when MOCA was used. The rhombi represent the pooled SMD for this association.

Study

ID
$\%$

$\operatorname{SMD}(95 \% \mathrm{Cl}) \quad$ Weight

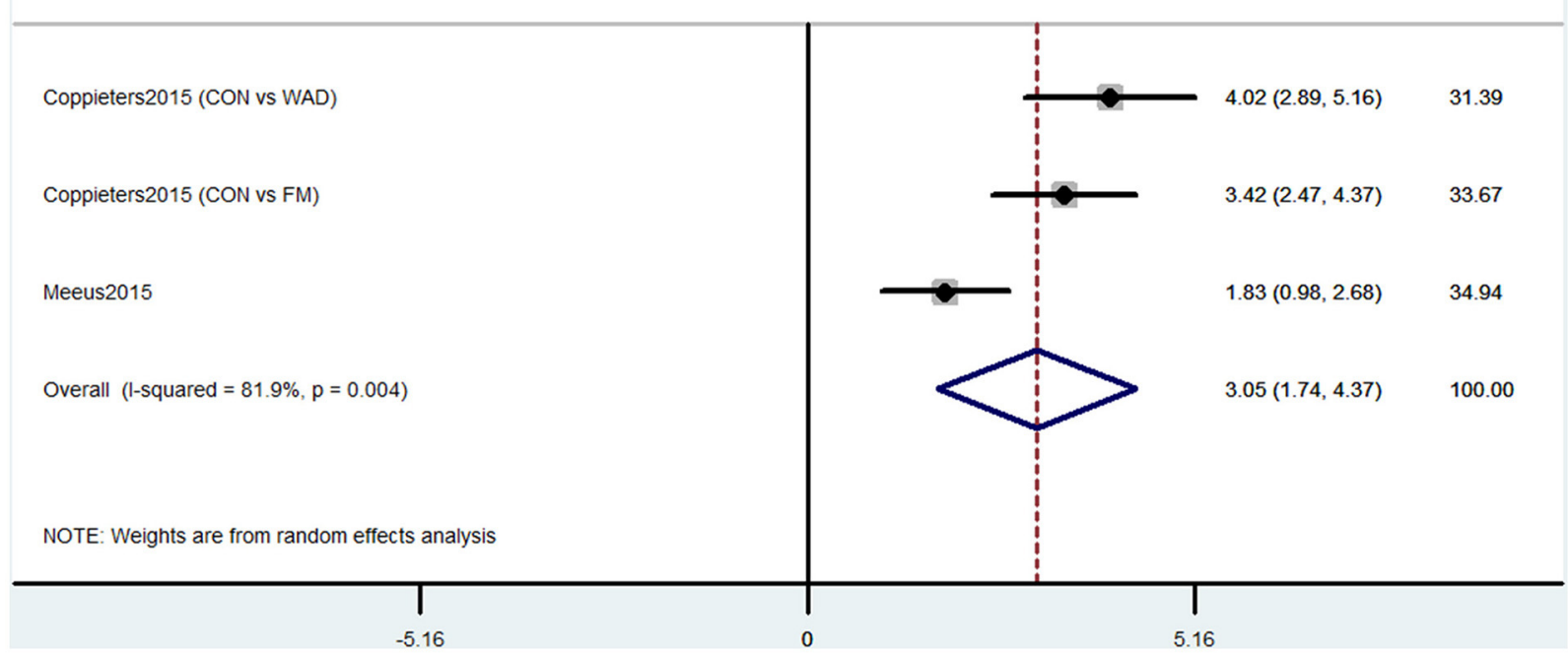

FIGURE 4 | Forest plot of the SMD and 95\% Cl from a random-effects meta-analysis for the association between chronic pain and incidence of cognitive decline when PVT was used. The rhombi represent the pooled SMD for this association. CON, control group; WAD, whiplash-associated disorder group; FM, fibromyalgia syndrome group. 


\section{How Cognitive Decline Was Evaluated-Tests and Test Outcomes}

Among the 37 included studies, four studies used ICD to identify the cognitive decline diseases, six studies contained 10 comparisons that used SF-36 mental component summary, six studies contained nine comparisons that used MMSE, and four studies used MOCA. In addition, two studies contained three comparisons that used PVT, two studies contained three comparisons that used OSPAN, and two studies used RBANS memory component to evaluate cognition function. Besides these, which can be analyzed, there were 11 studies that used other methods, which could not be analyzed. Four studies contained four comparisons that used different parts of the WAIS scale. Other studies used the Stroop test, MFE-30, SKT, MDS, TICS, STMS, and CNTAB, each contained one comparison.

\section{Meta-Analysis Outcomes}

\section{Outcome 1: Results for Short-Form 36 Health Survey Questionnaire Mental Component}

Short-form 36 health survey questionnaire was used by six studies containing 10 comparisons to evaluate the cognitive decline that mainly refers to mental health. Pooled results of these studies showed that $\mathrm{CP}$ was associated with cognitive decline $(\mathrm{SMD}=$
$-1.50,95 \% \mathrm{CI}=-2.19$ to -0.81$)$. The patients in the pain group were more likely to get the mental problem (Figure 2).

\section{Outcome 2: Results for Montreal Cognitive Assessment}

Four studies used MOCA to evaluate cognitive decline. The pooled results of these studies showed that CP was associated with cognitive decline (SMD $=-1.11,95 \% \mathrm{CI}=-1.60$ to $-0.61)$. The patients in the pain group were more likely to get low MOCA scores (Figure 3).

\section{Outcome 3: Results for Performance Validity Testing}

Performance validity testing was used by two studies containing three comparisons to evaluate the cognitive decline. The PVT has been validated as a measure of sustained attention, alertness, and simple reaction time. The pooled results showed that $\mathrm{CP}$ was associated with cognitive decline $(\mathrm{SMD}=3.05,95 \% \mathrm{CI}=1.74$ to 4.37 ). The patients in the pain group were more likely to have poor cognitive performance (Figure 4).

\section{Outcome 4: Results for Operation Span}

Operation span was used by two studies containing three comparisons to evaluate the cognitive decline. This task was used to assess working memory capacity. The pooled results showed that $\mathrm{CP}$ was associated with cognitive decline $(\mathrm{SMD}=-1.83$,

\begin{tabular}{|c|c|c|}
\hline Study & & $\%$ \\
\hline ID & $\mathrm{SMD}(95 \% \mathrm{Cl})$ & Weight \\
\hline Coppieters2015 (CON vs WAD) & $-2.09(-2.89,-1.28)$ & 33.15 \\
\hline Coppieters2015 (CON vs FM) & $-2.70(-3.53,-1.86)$ & 32.73 \\
\hline Meeus2015 & $-0.75(-1.48,-0.02)$ & 34.12 \\
\hline Overall $(I-$ squared $=84.4 \%, p=0.002)$ & $-1.83(-2.98,-0.68)$ & 100.00 \\
\hline \multicolumn{3}{|l|}{ NOTE: Weights are from random effects analysis } \\
\hline-3.53 & & \\
\hline
\end{tabular}




\begin{tabular}{|c|c|c|}
\hline Study & & $\%$ \\
\hline ID & OR $(95 \% \mathrm{Cl})$ & Weight \\
\hline Hagen2013 & $2.67(2.15,3.30)$ & 24.82 \\
\hline Kaiho2017 & $0.88(0.71,1.10)$ & 24.75 \\
\hline Tzeng2017 & $1.19(0.99,1.42)$ & 25.16 \\
\hline Ikram2019 & $2.20(1.86,2.61)$ & 25.27 \\
\hline Overall $(I-$ squared $=96.0 \%, p=0.000)$ & $1.58(0.97,2.56)$ & 100.00 \\
\hline \multicolumn{3}{|l|}{ NOTE: Weights are from random effects analysis } \\
\hline $\begin{array}{c}1 \\
.303\end{array}$ & 3 & \\
\hline
\end{tabular}

$95 \% \mathrm{CI}=-2.98$ to -0.68$)$. The patients in the pain group were more likely to have poor working memory performance (Figure 5).

\section{Outcome 5: Results for International Classification of Diseases and Related Health Problems}

Four studies used ICD to evaluate cognitive decline. The types of cognitive decline defined in these four studies mainly contained dementia and Alzheimer's disease. Pooled results of these studies showed that $\mathrm{CP}$ was not associated with cognitive decline ( $\mathrm{OR}=1.58,95 \% \mathrm{CI}=0.97$ to 2.56 ) (Figure 6).

\section{Outcome 6: Results for Mini-Mental State Examination}

Six studies used MMSE to evaluate cognitive decline. Among these six studies, four studies containing five comparisons used MMSE primary scores as the results. The pooled results showed that $\mathrm{CP}$ is not associated with cognitive decline ( $\mathrm{SMD}=-0.42$, $95 \% \mathrm{CI}=-0.94$ to 0.10 ) (Figure 7). Also, three studies contained four comparisons that divided participants into normal cognition and impaired cognition due to the scores. The pooled studies also showed that $\mathrm{CP}$ was not associated with cognitive decline $(\mathrm{OR}=1.14,95 \% \mathrm{CI}=0.91$ to 1.42$)$ (Figure 8).

\section{Outcomes 7: Results for Repeatable Battery for the Assessment of Neuropsychological Status}

Two studies used the RBANS memory component to evaluate cognitive decline. The pooled results showed that $\mathrm{CP}$ was not associated with cognitive decline (SMD $=-0.06,95 \%$ $\mathrm{CI}=-0.37$ to 0.25 ) (Figure 9).

\section{DISCUSSION}

Cognition is a complex concept that includes learning, memory, language, executive function, attention, social cognition, and others (Sachdev et al., 2014). The evaluative method of cognition remains various, making it difficult for researchers to conduct clinical trials or meta-analyses. We performed the analysis due to the different methods for cognitive assessment used in the 37 included articles. Pooled results from the outcomes of our study reflect an opposite result. The results showed a consistent, significant effect between $\mathrm{CP}$ and cognitive decline when the methods of SF-36 mental component summary, MOCA, PVT, and OSPAN were used. However, the results provided no evidence for an effect when methods of ICD, MMSE, and RBANS were used. 


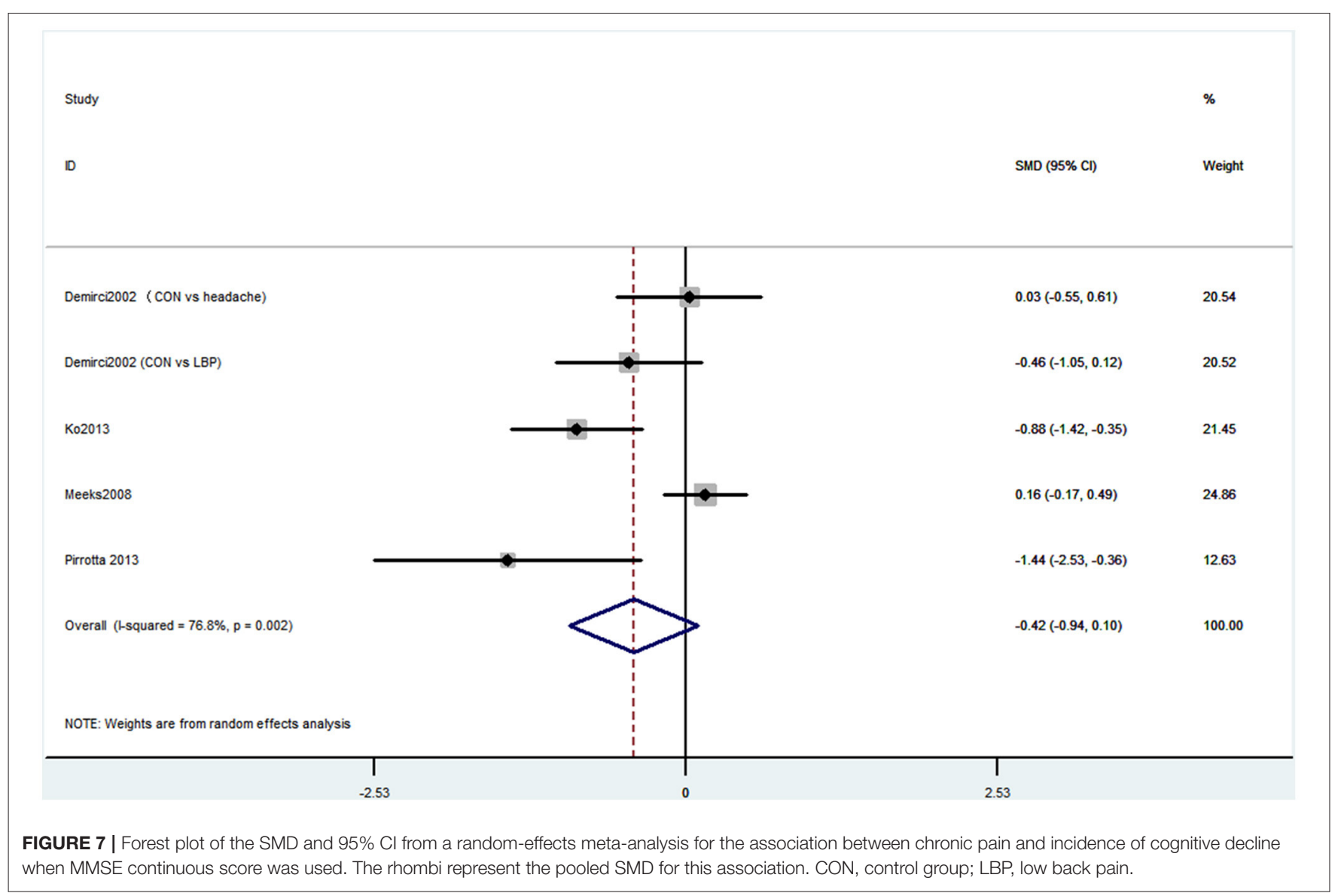

Numerous studies containing clinical and animal studies have shown CP could result in cognitive decline (Moriarty et al., 2011; Yang et al., 2014; Whitlock et al., 2017; Shiers et al., 2020). For example, Whitlock et al. (2017) found persistent pain was associated with accelerated memory decline and increased probability of dementia based on a cohort study with biennial interviews of 10,065 community-dwelling older adults. This article was published in the Journal of the American Medical Association Internal Medicine. Mechanism studies explain pain, and cognitive decline may share some same pathways (Moriarty et al., 2011; Phelps et al., 2021). Also, there have been some meta-analyses exploring the relationship between pain and some types of cognitive decline. For example, one metaanalysis showed $\mathrm{CP}$ was associated with memory deficits but only in behavioral outcomes, whereas the physiological effects showed no effect (Berryman et al., 2013). Another meta-analysis focused on executive function showed that people with $\mathrm{CP}$ might have impaired executive function (Berryman et al., 2014). However, a recent meta-analysis showed persistent pain was not associated with the incidence of cognitive decline from prospective longitudinal studies (De Aguiar et al., 2020).

Our meta-analysis showed some evidence that CP might be related to cognitive impairment. Six studies containing 10 comparisons used SF-36 that show that CP was associated with cognitive decline. The SF-36 was used to assess physical function, mental health, and health-related quality of life (Brazier et al., 1992). These six studies were from different countries, and the heterogeneity was high. Meanwhile, the pain types of these studies were different, four studies were CP without any subgroups, one study contained both whiplash-associated disorder and FM (Coppieters et al., 2015), and one study only contained FM (Martinsen et al., 2014). These factors together may induce high heterogeneity. Studies using MOCA also showed that $\mathrm{CP}$ was associated with cognitive decline. MOCA is used to evaluate the global cognitive status and several cognitive domains: memory, attention, language, orientation, and visuospatial and executive function domains (Nasreddine et al., 2005). These studies also had high heterogeneity. Three studies were performed on headache patients, but one investigated CP without more detailed classification. Thus, more homogeneous controlled clinical trials are needed to confirm the results. The PVT has been validated as a measure of sustained attention, alertness, and simple reaction time. Two studies containing three comparisons used PVT also showed that $\mathrm{CP}$ was associated with cognitive decline. However, only two studies were included in this analysis. Therefore, the number of included participants may not be enough, and more studies are needed. Another evidence was that two studies using OSPAN to 


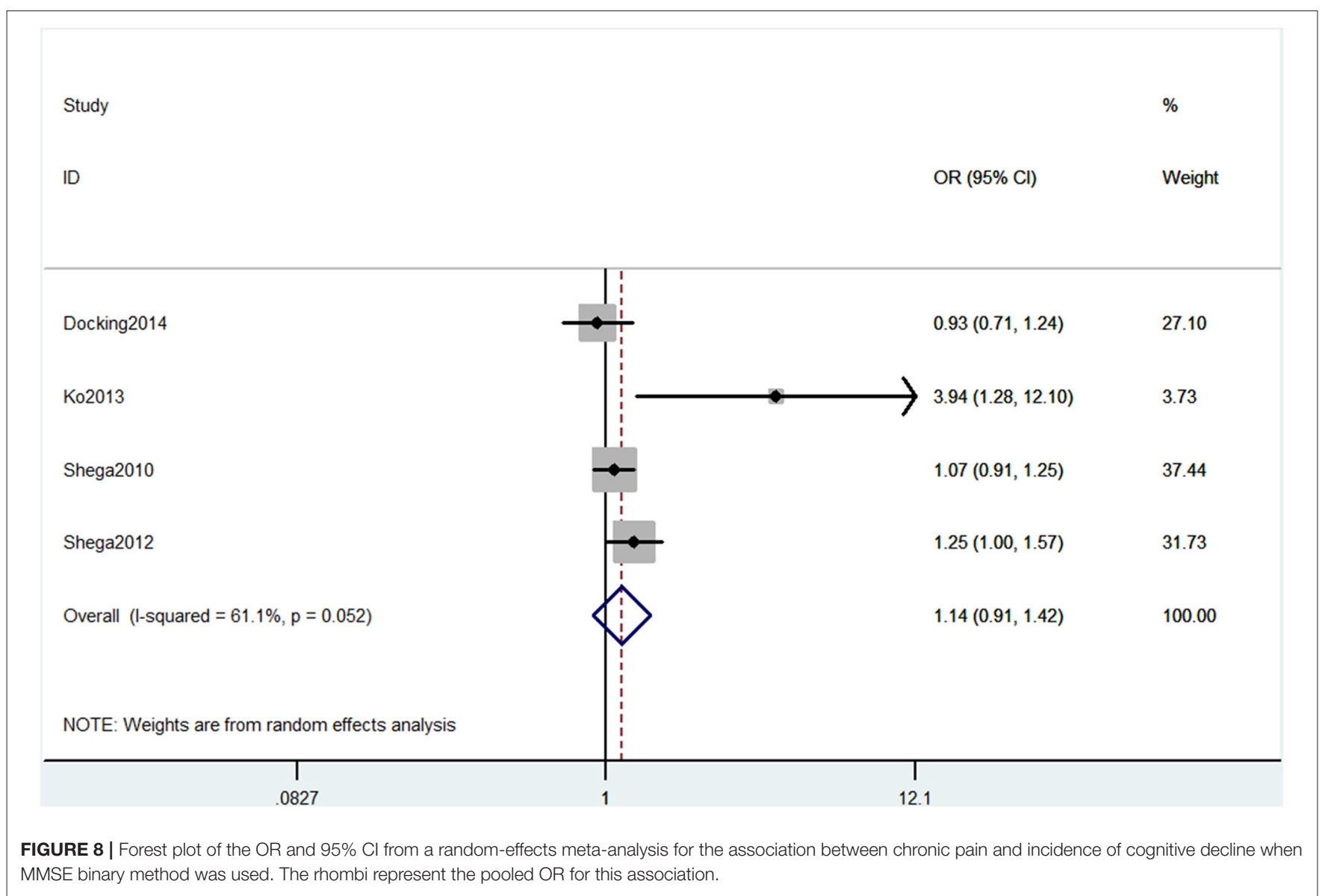

evaluate memory also verified the association between CP and cognitive decline (Quach et al., 2016). Besides, a study that used SKT also showed that preoperative CP distracted the attention before surgery and reduced the recovery of attention and memory abilities after the surgery in non-elderly patients (Gu et al., 2019). Moreover, animal studies showed that both rats and mice with CP could have cognitive disorders (Owoyele et al., 2021; Zhang et al., 2021).

The association between $\mathrm{CP}$ and cognitive decline is still unknown. An important key is that it is difficult to combine all the evaluative methods of cognition. In some methods such as MMSE, the higher the score, the worse the cognitive impairment. Some others, such as SF36, are opposite. In addition, some methods studied different types of cognitive impairment and could not be analyzed together. A total of 37 articles included in our study contained 15 methods that have been listed earlier. The sample size of studies using the same method was different. The study of Hagen et al. (2014) has the most sample size and far exceeded other studies. Another study with a larger sample size is Kaiho et al. (2017). Furthermore, these two studies both used the ICD method. However, the negative result of Kaiho et al. (2017) reversed the positive results of Hagen et al. (2014) and the other two studies in outcome 5 (Figure 6). Also, for other outcomes, whether the sample size is enough to support the positive results is unsure. So the conclusion needs a larger sample size and multicenter studies. Secondly, the evaluative accuracy of these methods is also different. Mini-Mental State Examination and MOCA, as the most basic methods, are regarded as brief screening tools (Nasreddine et al., 2005; Ciesielska et al., 2016). Wechsler Adult Intelligence Scale is also a comprehensive scale for neuropsychological status, including reasoning, processing speed, and working memory (Whipple Drozdick and Munro Cullum, 2011). Short-form 36 health survey questionnaire is a health-related evaluation tool, so the mental component summary and mental health part could only reflect some mental health (Brazier et al., 1992). Short test of mental status was found to be more sensitive than MMSE and can be used by clinicians to differentiate both normal cognition from MCI and MCI from probable Alzheimer's disease (Çebi et al., 2020). Performance validity testing, OSPAN, RBANS, and SKT are used to evaluate some aspects, including memory, attention, and reaction (Meeus et al., 2015; Van Der Leeuw et al., 2018a; Gu et al., 2019; Loring and Goldstein, 2019). Stroop test is used to mainly test reactions (Coppieters et al., 2015). Memory Failures of Everyday is used to assess memory problems (Samartin-Veiga et al., 2019). Minimus data set, TICS, and CNTAB are general scales but used 


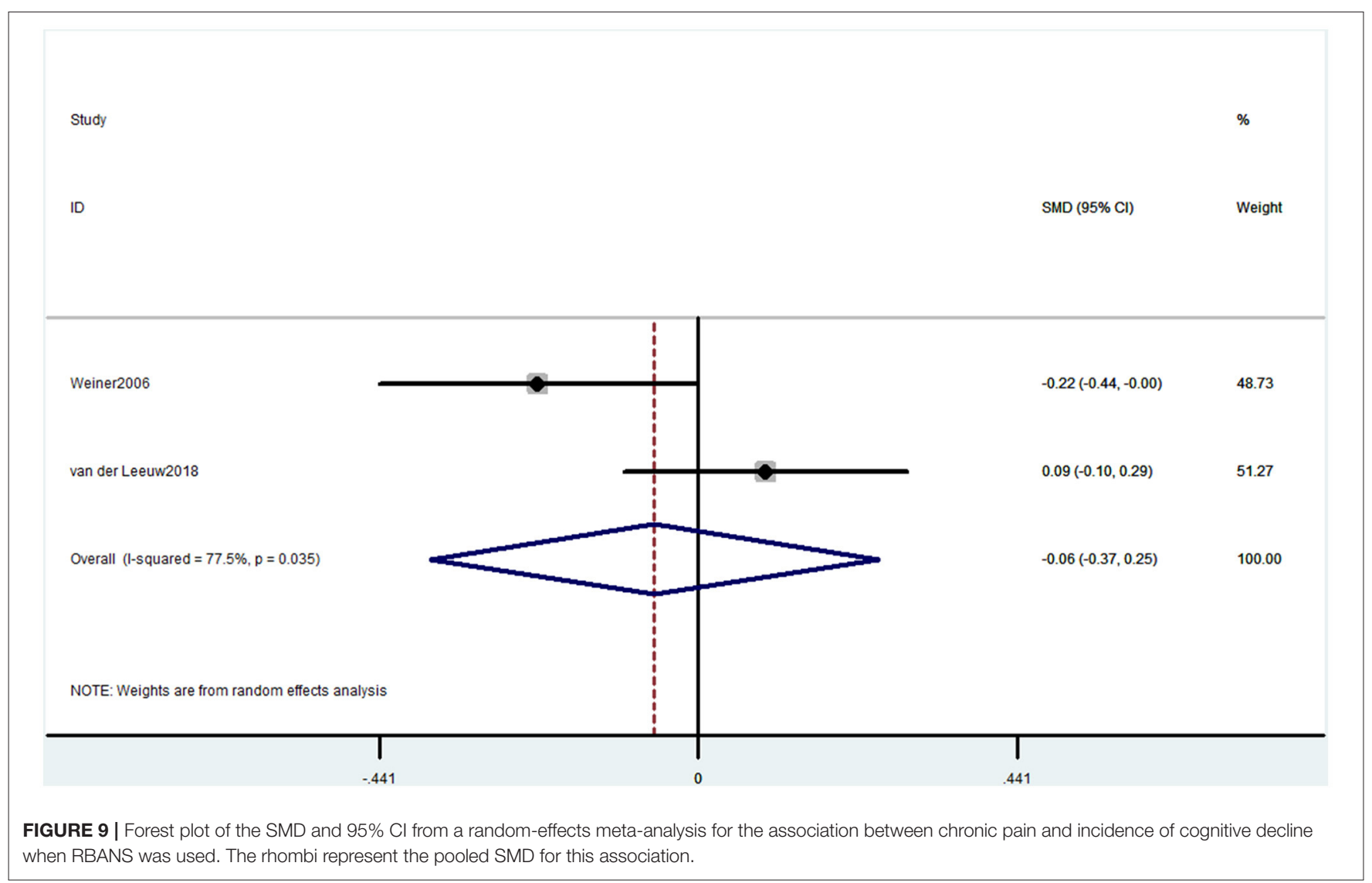

with low frequency (Pickering et al., 2014; Jordan et al., 2018; Van Der Leeuw et al., 2020). Therefore, each of these methods has its own advantages and disadvantages. Hopefully, future studies would compare these methods to confirm their accuracy for investigating.

Our meta-analysis also showed some negative results, possibly due to the cognitive evaluation method adopted. Mini-Mental State Examination was the essential evaluation of cognitive decline. However, only when the cognitive impairment is severe enough, this test works. Also, there have been some studies that suggested MMSE is less accurate than MOCA (Roalf et al., 2013; Pinto et al., 2019). As for RBANS, only two studies were included; the sample size was too small to account for the result. Besides, RBANS is a complex assessment containing many aspects (Weiner et al., 2006), and only one part of the two studies was identical. Also, one recent meta-analysis has found this controversial conclusion between persistent pain and cognitive function among the olds (De Aguiar et al., 2020). However, they did not care about the different cognitive evaluation methods. Therefore, we have a concern about their conclusion. It is important to make it comparable. Our risk of bias assessments has provided some recommendations for future studies. For example, acknowledged diagnostic criteria should be used for $\mathrm{CP}$ and cognitive decline. Also, it is critical for the future study to consider the following aspects, such as much more accurate screening of psychiatric disorders, blinded method, and calculation of sample size in advance. In addition, a clinical study of a large sample size should be performed, as many studies included only had small sample sizes.

\section{CONCLUSION}

In the present study, we had found that CP might be associated with cognitive decline when the cognitive, evaluative scales were used, including the SF-36 mental component summary, MOCA, PVT, and OSPAN. Future studies are needed with a unified cognitive evaluation method to clarify the association between $\mathrm{CP}$ and cognitive function.

\section{DATA AVAILABILITY STATEMENT}

The original contributions presented in the study are included in the article/Supplementary Material, further inquiries can be directed to the corresponding author/s.

\section{AUTHOR CONTRIBUTIONS}

CC and TZ: conception and design. CC: administrative support. XZ, RG, QZ, and CZ: collection and assembly of data. XZ, RG, 
and HC: data analysis and interpretation. All authors: manuscript writing and final approval of manuscript.

\section{FUNDING}

This study was funded by the National Natural Science Foundation of China (Nos. 81870858, 81500937, and 82171185 to CC), the National Key R\&D Program of China (No. 2018YFC2001800 to TZ), the National Natural Science Foundation of China (No. 81671062 to

\section{REFERENCES}

Berryman, C., Stanton, T. R., Bowering, K. J., Tabor, A., McFarlane, A., and Moseley, G. L. (2014). Do people with chronic pain have impaired executive function? A meta-analytical review. Clin. Psychol. Rev. 34, 563-579. doi: 10.1016/j.cpr.2014.08.003

Berryman, C., Stanton, T. R., Jane Bowering, K., Tabor, A., Mcfarlane, A., and Lorimer Moseley, G. (2013). Evidence for working memory deficits in chronic pain: a systematic review and meta-analysis. Pain 154, 1181-1196. doi: 10.1016/j.pain.2013.03.002

Brazier, J. E., Harper, R., Jones, N. M., O'cathain, A., Thomas, K. J., Usherwood, T., et al. (1992). Validating the SF-36 health survey questionnaire: new outcome measure for primary care. BMJ 305, 160-164. doi: 10.1136/bmj.305.68 46.160

Butterworth, P. A., Urquhart, D. M., Cicuttini, F. M., Menz, H. B., Strauss, B. J., Proietto, J., et al. (2014). Relationship between mental health and foot painRelationship between mental health and foot pain. Arthritis Care Res. (Hoboken) 66, 1241-1245. doi: 10.1002/acr.22292

Cebi, M., Babacan, G., ktem Tanör, and Gürvit, H. (2020). Discrimination ability of the Short Test of Mental Status (STMS) compared to the Mini Mental State Examination (MMSE) in the spectrum of normal cognition, mild cognitive impairment, and probable Alzheimer's disease dementia: The Turkish standardization study. J. Clin. Exp. Neuropsychol. 42, 450-458. doi: 10.1080/13803395.2020.1758633

Ciesielska, N., Sokołowski, R., Mazur, E., Podhorecka, M., Polak-Szabela, A., and Kedziora-Kornatowska, K. (2016). Is the Montreal Cognitive Assessment (MoCA) test better suited than the Mini-Mental State Examination (MMSE) in mild cognitive impairment (MCI) detection among people aged over 60 ? Meta-analysis. Psychiatr Pol. 50, 1039-1052. doi: 10.12740/PP/45368

Coppieters, I., Ickmans, K., Cagnie, B., Nijs, J., De Pauw, R., Noten, S., et al. (2015). Cognitive performance is related to central sensitization and healthrelated quality of life in patients with chronic whiplash-associated disorders and fibromyalgia. Pain Physician 18, E389-E402. doi: 10.36076/ppj.2015/ 18/E389

De Aguiar, G., Saraiva, M. D., Khazaal, E. J. B., De Andrade, D. C., Jacob-Filho, W., and Suemoto, C. K. (2020). Persistent pain and cognitive decline in older adults: a systematic review and meta-analysis from longitudinal studies. Pain 161, 2236-2247. doi: 10.1097/j.pain.0000000000001932

Demirci, S., and Savas, S. (2002). The auditory event related potentials in episodic and chronic pain sufferers. Eur. J. Pain 6, 239-244. doi: 10.1053/eujp.2001.0342

Docking, R. E., Fleming, J., Brayne, C., Zhao, J., Macfarlane, G. J., and Jones, G. T. (2014). Pain reporting in older adults: the influence of cognitive impairment - Results from the Cambridge city $>75$ cohort study. Br J Pain 8, 119-124. doi: $10.1177 / 2049463714527437$

Dos Santos Ferreira, K., Oliver, G. Z., Thomaz, D. C., Teixeira, C. T., and Foss, M. P. (2016). Cognitive deficits in chronic pain patients, in a brief screening test, are independent of comorbidities and medication use. Arq. Neuropsiquiatr. 74, 361-366. doi: 10.1590/0004-282X20160071

Fernández-Lao, C., Galiano-Castillo, N., Cantarero-Villanueva, I., Martín-Martín, L., Prados-Olleta, N., and Arroyo-Morales, M. (2016). Analysis of pressure pain hypersensitivity, ultrasound image, and quality of life in patients with chronic plantar pain: a preliminary study. Pain Med. 17, 1530-1541. doi: $10.1093 / \mathrm{pm} / \mathrm{pnv} 022$
TZ), China Postdoctoral Science Foundation (Grant No. 2020M673234 to RG), and the Science and Technology Plan Project of Sichuan Province (No. 2020YJ0051 to $\mathrm{CC})$.

\section{SUPPLEMENTARY MATERIAL}

The Supplementary Material for this article can be found online at: https://www.frontiersin.org/articles/10.3389/fnins. 2021.737874/full\#supplementary-material

GBD Disease and Injury Incidence and Prevalence Collaborators (2017). Global, regional, and national incidence, prevalence, and years lived with disability for 328 diseases and injuries for 195 countries, 1990-2016: a systematic analysis for the Global Burden of Disease Study 2016. Lancet 390, 1211-1259. doi: 10.1016/S0140-6736(17)32154-2

Gu, H., Deng, X., Lv, Y., Chen, Q., and Yu, W. (2019). Preoperational chronic pain impairs the attention ability before surgery and recovery of attention and memory abilities after surgery in non-elderly patients. J. Pain Res. 12, 151-158. doi: $10.2147 /$ JPR.S178118

Hagen, K., Stordal, E., Linde, M., Steiner, T. J., Zwart, J. A., and Stovner, L. J. (2014). Headache as a risk factor for dementia: a prospective population-based study. Cephalalgia 34, 327-335. doi: 10.1177/03331024135 13181

Higgins, J. P., and Green, S. (2008). Cochrane Handbook for Systematic Reviews of Interventions. Chichester, UK: Wiley-Blackwell. doi: 10.1002/9780470712184

Ikram, M., Innes, K., and Sambamoorthi, U. (2019). Association of osteoarthritis and pain with Alzheimer's diseases and related dementias among older adults in the United States. Osteoarthr. Cartil. 27, 1470-1480. doi: 10.1016/j.joca.2019.05.021

Jonsson, T., Christrup, L. L., Højsted, J., Villesen, H. H., Albjerg, T. H., Ravn-Nielsen, L. V., et al. (2011). Symptoms and side effects in chronic non-cancer pain: patient report vs. systematic assessment. Acta Anaesthesiol. Scand. 55, 69-74. doi: 10.1111/j.1399-6576.2010.0 2329.x

Jordan, J., Crowe, M., Gillon, D., Mccall, C., Frampton, C., and Jamieson, H. (2018). Reduced pain reports with increasing cognitive impairment in older persons in New Zealand. Am. J. Alzheimers. Dis. Other Demen. 33, 463-470. doi: $10.1177 / 1533317518772685$

Kaiho, Y., Sugawara, Y., Sugiyama, K., Tomata, Y., Endo, Y., Toyama, H., et al. (2017). Impact of pain on incident risk of disability in elderly Japanese: cause-specific analysis. Anesthesiology 126, 688-696. doi: 10.1097/ALN.0000000000001540

Ko, H. J., Seo, S. J., Youn, C. H., Kim, H. M., and Chung, S. E. (2013). The association between pain and depression, anxiety, and cognitive function among advanced cancer patients in the hospice ward. Korean J. Fam. Med. 34, 347-356. doi: 10.4082/kjfm.2013.34. 5.347

Kotb, M. A., Kamal, A. M., Al-Malki, D., Abd El Fatah, A. S., and Ahmed, Y. M. (2020). Cognitive performance in patients with chronic tension-type headache and its relation to neuroendocrine hormones. Egypt J Neurol Psychiatr Neurosurg 56, 16. doi: 10.1186/s41983-020-0150-3

Latysheva, N., Filatova, E., Osipova, D., and Danilov, A. B. (2020). Cognitive impairment in chronic migraine: a cross-sectional study in a clinicbased sample. Arq. Neuropsiquiatr. 78, 133-138. doi: 10.1590/0004-282x201 90159

Loring, D. W., and Goldstein, F. C. (2019). If invalid PVT scores are obtained, can valid neuropsychological profiles be believed? Arch. Clin. Neuropsychol. 34, 1192-1202. doi: 10.1093/arclin/acz028

Martinsen, S., Flodin, P., Berrebi, J., Löfgren, M., Bileviciute-Ljungar, I., Ingvar, M., et al. (2014). Fibromyalgia patients had normal distraction related pain inhibition but cognitive impairment reflected in caudate nucleus and hippocampus during the Stroop Color Word Test. PLoS ONE 9, e108637. doi: 10.1371/journal.pone.0108637 
Mazza, S., Frot, M., and Rey, A. E. (2018). A comprehensive literature review of chronic pain and memory. Prog. Neuropsychopharmacol. Biol. Psychiatry 87, 183-192. doi: 10.1016/j.pnpbp.2017.08.006

Meeks, T. W., Dunn, L. B., Kim, D. S., Golshan, S., Sewell, D. D., Atkinson, J. H., et al. (2008). Chronic pain and depression among geriatric psychiatry inpatients. Int. J. Geriatr. Psychiatry 23, 637-642. doi: 10.1002/gps.1954

Meeus, M., Van Oosterwijck, J., Ickmans, K., Baert, I., Coppieters, I., Roussel, N., et al. (2015). Interrelationships between pain processing, cortisol and cognitive performance in chronic whiplash-associated disorders. Clin. Rheumatol. 34, 545-553. doi: 10.1007/s10067-013-2446-5

Moher, D., Liberati, A., Tetzlaff, J., Altman, D. G., and PRISMA Group. (2009). Preferred reporting items for systematic reviews and meta-analyses: the PRISMA statement. PLoS Med. 6:e1000097. doi: 10.1371/journal.pmed.1000097

Moriarty, O., Mcguire, B. E., and Finn, D. P. (2011). The effect of pain on cognitive function: a review of clinical and preclinical research. Prog. Neurobiol. 93, 385-404. doi: 10.1016/j.pneurobio.2011.01.002

Nakai, Y., Makizako, H., Kiyama, R., Tomioka, K., Taniguchi, Y., Kubozono, T., et al. (2020). Association between chronic pain and physical frailty in community-dwelling older adults. Int. J. Environ. Res. Public Health 16, 1330. doi: 10.3390/ijerph16081330

Nasreddine, Z. S., Phillips, N. A., Bédirian, V., Charbonneau, S., Whitehead, V., Collin, I., et al. (2005). The Montreal Cognitive Assessment, MoCA: a brief screening tool for mild cognitive impairment. J. Am. Geriatr. Soc. 53, 695-699. doi: 10.1111/j.1532-5415.2005.53221.x

Ojeda, B., Dueñas, M., Salazar, A., Mico, J. A., Torres, L. M., and Failde, I. (2018). Factors influencing cognitive impairment in neuropathic and musculoskeletal pain and fibromyalgia. Pain Med. 19, 499-510. doi: 10.1093/pm/pnx024

Öncü, J., Ilişer, R., and Kuran, B. (2015). Cognitive complaints in patients with fibromyalgia versus older-aged women: case control study. S. Afr. J. Psychiatr. 18:2. doi: 10.4172/Psychiatry.1000242

Owoyele, B. V., Bakare, A. O., Ayinla, M. T., Adeshina, K. A., Onietan, D., and Azeez, S. O. (2021). Antinociceptive effects of lead acetate in sciatic nerve chronic constriction injury model of peripheral neuropathy in male Wistar rats. Naunyn Schmiedebergs. Arch. Pharmacol. 394, 117-125. doi: 10.1007/s00210-020-01951-w

Phelps, C. E., Navratilova, E., and Porreca, F. (2021). Cognition in the chronic pain experience: preclinical Insights. Trends Cogn. Sci. 25, 365-376. doi: 10.1016/j.tics.2021.01.001

Pickering, G., Pereira, B., Clère, F., Sorel, M., De Montgazon, G., Navez, M., et al. (2014). Cognitive function in older patients with postherpetic neuralgia. Pain Pract. 14, E1-E7. doi: 10.1111/papr.12079

Pidal-Miranda, M., González-Villar, A. J., Carrillo-De-La-Peña, M. T., Andrade, E., and Rodríguez-Salgado, D. (2018). Broad cognitive complaints but subtle objective working memory impairment in fibromyalgia patients. PeerJ. 6:e5907. doi: $10.7717 /$ peerj.5907

Pinto, T. C. C., Machado, L., Bulgacov, T. M., Rodrigues-Júnior, A. L., Costa, M. L. G., Ximenes, R. C. C., et al. (2019). Is the Montreal Cognitive Assessment (MoCA) screening superior to the Mini-Mental State Examination (MMSE) in the detection of mild cognitive impairment (MCI) and Alzheimer's Disease (AD) in the elderly? Int. Psychogeriatr. 31, 491-504. doi: $10.1017 /$ S1041610218001370

Pirrotta, R., Jeanmonod, D., Mcaleese, S., Aufenberg, C., Opwis, K., Jenewein, J., et al. (2013). Cognitive functioning, emotional processing, mood, and personality variables before and after stereotactic surgery: a study of 8 cases with chronic neuropathic pain. Neurosurgery 73, 121-128. doi: 10.1227/01.neu.0000429845.06955.70

Qu, P., Yu, J. X., Xia, L., and Chen, G. H. (2018). Cognitive performance and the alteration of neuroendocrine hormones in chronic tension-type headache. Pain Pract. 18, 8-17. doi: 10.1111/papr.12574

Quach, D., Jastrowski Mano, K. E., and Alexander, K. (2016). A randomized controlled trial examining the effect of mindfulness meditation on working memory capacity in adolescents. J. Adolesc. Health 58, 489-496. doi: 10.1016/j.jadohealth.2015.09.024

Roalf, D. R., Moberg, P. J., Xie, S. X., Wolk, D. A., Moelter, S. T., and Arnold, S. E. (2013). Comparative accuracies of two common screening instruments for classification of Alzheimer's disease, mild cognitive impairment, and healthy aging. Alzheimers. Dement. 9, 529-537. doi: 10.1016/j.jalz.2012.10.001
Sachdev, P. S., Blacker, D., Blazer, D. G., Ganguli, M., Jeste, D. V., Paulsen, J. S., et al. (2014). Classifying neurocognitive disorders: the DSM-5 approach. Nat. Rev. Neurol. 10, 634-642. doi: 10.1038/nrneurol.2014.181

Samartin-Veiga, N., González-Villar, A. J., and Carrillo-De-La-Peña, M. T. (2019). Neural correlates of cognitive dysfunction in fibromyalgia patients: reduced brain electrical activity during the execution of a cognitive control task. Neuroimage Clin. 23:101817. doi: 10.1016/j.nicl.2019.101817

Santangelo, G., Russo, A., Trojano, L., Falco, F., Marcuccio, L., Siciliano, M., et al. (2016). Cognitive dysfunctions and psychological symptoms in migraine without aura: a cross-sectional study. J. Headache Pain 17:76. doi: 10.1186/s10194-016-0667-0

Saraiva, M. D., Suzuki, G. S., Lin, S. M., De Andrade, D. C., Jacob-Filho, W., and Suemoto, C. K. (2018). Persistent pain is a risk factor for frailty: a systematic review and meta-analysis from prospective longitudinal studies. Age Ageing 47, 785-793. doi: 10.1093/ageing/afy104

Schepker, C. A., Leveille, S. G., Pedersen, M. M., Ward, R. E., Kurlinski, L. A., Grande, L., et al. (2016). Effect of pain and mild cognitive impairment on mobility. J. Am. Geriatr. Soc. 64, 138-143. doi: 10.1111/jgs.13869

Shega, J. W., Andrew, M., Hemmerich, J., Cagney, K. A., Ersek, M., Weiner, D. K., et al. (2012). The relationship of pain and cognitive impairment with social vulnerability-an analysis of the Canadian Study of Health and Aging. Pain Med. 13, 190-197. doi: 10.1111/j.1526-4637.2011.01309.x

Shega, J. W., Weiner, D. K., Paice, J. A., Bilir, S. P., Rockwood, K., Herr, K., et al. (2010). The association between noncancer pain, cognitive impairment, and functional disability: an analysis of the Canadian study of health and aging. $J$. Gerontol. A Biol. Sci. Med. Sci. 65, 880-886. doi: 10.1093/gerona/glq039

Shiers, S., Mwirigi, J., Pradhan, G., Kume, M., Black, B., and Barragan-Iglesias, P. (2020). Reversal of peripheral nerve injury-induced neuropathic pain and cognitive dysfunction via genetic and tomivosertib targeting of MNK. Neuropsychopharmacology 45, 524-533. doi: 10.1038/s41386-019-0537-y

Treede, R. D., Rief, W., Barke, A., Aziz, Q., Bennett, M. I., Benoliel, R., et al. (2019). Chronic pain as a symptom or a disease: the IASP Classification of Chronic Pain for the International Classification of Diseases (ICD-11). Pain 160, 19-27. doi: $10.1097 / j$.pain.0000000000001384

Tzeng, N. S., Chung, C. H., Lin, F. H., Yeh, C. B., Huang, S. Y., Lu, R. B., et al. (2017). Headaches and Risk of Dementia. Am. J. Med. Sci. 353, 197-206. doi: 10.1016/j.amjms.2016.12.014

Van Der Leeuw, G., Ayers, E., Blankenstein, A. H., Van Der Horst, H. E., and Verghese, J. (2020). The association between pain and prevalent and incident motoric cognitive risk syndrome in older adults. Arch. Gerontol. Geriatr. 87:103991. doi: 10.1016/j.archger.2019.103991

Van Der Leeuw, G., Ayers, E., Leveille, S., Blankenstein, A., Van Der Horst, H., and Verghese, J. (2018b). The effect of pain severity on major cognitive impairment in older adults with pain. J. Am. Geriatr. Soc. 66, S132-S133.

Van Der Leeuw, G., Ayers, E., Leveille, S. G., Blankenstein, A. H., Van Der Horst, H. E., and Verghese, J. (2018a). The effect of pain on major cognitive impairment in older adults. J. Org. Chem. 19, 1435-1444. doi: 10.1016/j.jpain.2018.06.009

Veronese, N., Koyanagi, A., Solmi, M., Thompson, T., Maggi, S., Schofield, P., et al. (2018). Pain is not associated with cognitive decline in older adults: a four-year longitudinal study. Biomed. Res. Int. 115, 92-96. doi: 10.1016/j.maturitas.2018.07.001

Walteros, C., Sánchez-Navarro, J. P., Muñoz, M. A., Martínez-Selva, J. M., Chialvo, D., and Montoya, P. (2011). Altered associative learning and emotional decision making in fibromyalgia. J. Psychosom. Res. 70, 294-301. doi: 10.1016/j.jpsychores.2010.07.013

Wang, J., Xu, W., Sun, S., and Yu, S. (2018). Headache disorder and the risk of dementia: a systematic review and meta-analysis of cohort studies. J. Headache Pain 19:95. doi: 10.1186/s10194-018-0925-4

Weiner, D. K., Rudy, T. E., Morrow, L., Slaboda, J., and Lieber, S. (2006). The relationship between pain, neuropsychological performance, and physical function in community-dwelling older adults with chronic low back pain. Pain Med. 7, 60-70. doi: 10.1111/j.1526-4637.2006.00091.x

Whipple Drozdick, L., and Munro Cullum, C. (2011). Expanding the ecological validity of WAIS-IV and WMS-IV with the Texas functional living scale. Assessment 18, 141-155. doi: 10.1177/1073191110382843

Whitlock, E. L., Diaz-Ramirez, L. G., Glymour, M. M., Boscardin, W. J., Covinsky, K. E., and Smith, A. K. (2017). Association between persistent pain and memory decline and dementia in a longitudinal cohort of 
elders. JAMA Intern. Med. 177, 1146-1153. doi: 10.1001/jamainternmed.2017. 1622

Yang, L., Xin, X., Zhang, J., Zhang, L., Dong, Y., Zhang, Y., et al. (2014). Inflammatory pain may induce cognitive impairment through an interlukin6-dependent and postsynaptic density-95-associated mechanism. Anesth Analg 119, 471-480. doi: 10.1213/ANE.0000000000000279

Zhang, G. F., Zhou, Z. Q., Guo, J., Gu, H. W., Su, M. Z., Yu, B. C., et al. (2021). Histone deacetylase 3 in hippocampus contributes to memory impairment after chronic constriction injury of sciatic nerve in mice. Pain 162, 382-395. doi: 10.1097/j.pain.0000000000002056

Conflict of Interest: The authors declare that the research was conducted in the absence of any commercial or financial relationships that could be construed as a potential conflict of interest.
Publisher's Note: All claims expressed in this article are solely those of the authors and do not necessarily represent those of their affiliated organizations, or those of the publisher, the editors and the reviewers. Any product that may be evaluated in this article, or claim that may be made by its manufacturer, is not guaranteed or endorsed by the publisher.

Copyright $\odot 2021$ Zhang, Gao, Zhang, Chen, Wang, Zhao, Zhu and Chen. This is an open-access article distributed under the terms of the Creative Commons Attribution License (CC BY). The use, distribution or reproduction in other forums is permitted, provided the original author(s) and the copyright owner(s) are credited and that the original publication in this journal is cited, in accordance with accepted academic practice. No use, distribution or reproduction is permitted which does not comply with these terms. 